\title{
Team Working Practices and Team Orientation of Employee: A Comparative Study between the State and Private Banks in Sri Lanka
}

\author{
A. Anuja \\ Lecturer \\ Department of Business and Management Studies \\ Faculty of Communication and Business Studies, Trincomalee Campus \\ and \\ A. Anton Arulrajah \\ Senior Lecturer \\ Department of Management, Eastern University, Sri Lanka
}

\begin{abstract}
An empirical knowledge gap was observed regarding Team Working Practices (TWP) and Team Orientation of Employee (TOE) of the selected bank branches (State Bank 1, State Bank 2, Private Bank 1 and Private Bank 2) in Sri Lanka. In general, the selected banks have formal and informal practices regarding team work and also promoting team work and team culture among their employees to flourish team orientation. Therefore, in order to fill this empirical knowledge gap, this study was conducted with three research objectives such as to explore the team working practices, level of team orientation of employee of selected state and private sector bank branches and also to investigate the differences in team orientation of employee according to the employee's gender, age, education, grade, working section and experience. In order to achieve the first objective of this study data were collected from the secondary sources, mainly from last four years annual reports and content analysis was applied. In this case, the unit of analysis was bank. Regarding second and third objectives primary data were collected from 115 employees of selected bank branches and the structured questionnaire was administered to collect the data. The data were analyzed by using univariate (descriptive measures such as mean and standard deviation) and cross-tabulation analyses. In this case, the unit of analysis was bank employee.
\end{abstract}

In connection with first objective, findings of the study revealed that both state and private sector banks are practicing various team working practices, but relatively private sector banks have more team practices than state sector banks. In private sector, PB-1 has more team practices than PB-2. Regarding the second objective, the results of the study showed that there is a higher level of team orientation among the employees of the four banks (mean value was above 3.5) but there were slight differences observed. The mean values for the $P B-1, P B-2, S B-1$ and $S B-2$ were $4.19,4.18,3.94$ and 3.77 respectively. Crosstabulating of the overall level of team-orientation with gender, age, education, grade, working section and experiences of employees revealed that there are some differences regarding the third objective. Finding of the study will be useful and important in understanding empirical knowledge regarding the concepts of team working practices and team orientation of employee from the banking sector perspective.

Key Words: Team, Teamwork, Team Working Practices, Team Orientation, Bank Employee 


\section{Background of the Study}

Nowadays many business organisations are practicing or try to practice team works in Sri Lanka including banks. Especially banks are promoting team works, team culture and team based HRM practices to strength the level of team orientation among their employees. Some banks attempt to show their identities as unique teams with their bank names in the banking industry. Some banks are struggling to build and practice team culture among their employees. Some banks have taken initial steps in the team building process. All together, banks realized the importance of teams in their highly competitive business environment and use various practices, techniques, tools and motivational mechanism to cultivate team orientation among their workforce in Sri Lanka.

The concepts of team working practices and team orientation of employee are not new to the organizations. Team is a fundamental work unit of organizational structure. Nowadays, almost managers of every organization talk about teams, but it takes more than an ad hoc group of people to make up a winning team. In the Sri Lankan commercial banking industry also the team or team working is one of the popular HRM practices among the banks. Every bank tries to show it as a unique team in the competitive banking environment in Sri Lanka.

In considering above background about team and team work in the organisations in general and commercial banking sector in Sri Lanka, it is worthwhile to explore the team working practices and level of team orientation of employee of state and private sector banks in Sri Lanka, because these banks also practice team works or try to practice team culture among their employees. This kind of exploration would be useful in gaining empirical knowledge about team working practices and team orientation of employee in the Sri Lankan banking context.

Therefore it necessitates a systematic research study to explore and highlight above aspect. Based on above research background and generally observed empirical knowledge gap three research questions were formulated:

1. What are the team working practices available among the selected state and private sector banks?

2. What is the level of team orientation of selected state and private sector bank employees? and

3. Whether team orientation of employees of state and private sector banks in the Trincomalee district gets differed according to the gender, age, education, grade, working section and experiences of employees?

\section{Objectives of the Study}

Based on the above research questions following research objectives were formulated:

1. To explore the team working practices of selected state and private sector banks.

2. To find out the level of team orientation of employee of selected state and private banks.

3. To investigate whether team orientation of employee gets differed according to the employee's gender, age, education, grade, working section and experience. 


\section{Scope of the Study}

It is impractical to examine team working practices, level of team orientation and differences in the team orientation of employee according to the gender, age, education grade, working section and experience of all banks which are operating in Sri Lanka in one cross sectional study. Therefore the researchers have narrowed down the scope of this study to the Trincomalee district and also selected only four licensed domestic banks, two from each sector (state and private). From the both sectors State Bank 1 (SB-1), State Bank 2 (SB-2), Private Bank 1 (PB-1) and Private Bank 2 (PB-2) were selected to carry out this research study.

\section{Team and Team Working}

\section{Literature Review}

According to Shaw (1981) a team is a group of people who work together. Team is a group of people with a high degree of interdependence geared toward the achievement of a goal or the completion of a task (Parker and Pankowski, 1990). Team is a minimum of two people working together towards shared goals. It may involve similar people working in parallel, where the team benefits are mostly about minimizing costs by sharing information and resources (Clegg, 2000). Kleiman (1997) identified 'team work' as one of the sixteen HRM practices that enhance competitive advantage of a firm.

In considering these definitions we can observe some salient features of teams in an orgnisational setting. First, teams are made up of two or more people. Second, the people in teams work together on a continuing basis for the duration of the team. Third, people in a team share a goal and specific tasks. Fourth, complementary skills are needed. Fifth, team members are mutually accountable to each other. Finally in an organisational setting, employees are frequently assigned to complete assignments as teams in the working environment. For this research purpose, we redefine team in the perspective of banking environment as two or more people with required complementary skills who are committed and mutually accountable to each other in order to achieve common goals and tasks in a bank.

\section{Team Orientation of Employee}

Team orientation refers to an individual's propensity for functioning as part of a team and the degree to which individuals prefer to work in group settings for task accomplishment (Driskell and Salas, 1992). Team orientation is generally viewed as stable enough to affect how individuals respond to a particular situation, but can be changed over time through experience (Wageman, 1995; Eby and Dobbins, 1997). Team orientation is defined as the degree to which the organisational members stress collaboration and cooperation in performing business activities and in making business decisions (Hult and Nichols, 1999). Team orientation is a general disposition inclining some individuals toward working in groups or teams (O'Shea et al, 2004). Team orientation means state of being directed as a team (Anton Arulrajah and Opatha, 2012). From the above definitions of team orientations, for this study purpose, we can define that team orientation means extent to which the employees of a bank have really directed and committed towards team works. On the other hand it is about state of being orientated or directed towards in team works in achieving bank's goals and objectives. 


\section{Measuring Team Orientation of Employee}

A search of the literature revealed only few existing measurement scales for team orientation. In order to achieve the study objectives an instrument was developed to measure the degree of team orientation among the members of state and private banks based on Hult and Nichols (1999) model.

\section{Measures}

In this study Team Orientation of employee (TOE) was measured by using 29 items representing 6 dimensions designed to tap the following team orientation facets in a bank branch context such as Team spirit ( 5 items), Cross functional teamwork (5 items), Commonality of purpose (5 items), Agreement of organizational vision (4 items), Leadership at branch level (5 items) and Communication (5 items). Out of these six dimensions, first five dimensions were directly adapted from Hult and Nichols (1999) who were studied team orientation in global purchasing unit of a Fortune 500 multinational services organization based on a sample of 179 domestic and 167 international strategic business units (Cronbach's alpha of 0.83). The last dimension (communication) was incorporated by the researchers in considering importance of communication in promoting teams in a bank branch context. Item responses were coded on a five-point Likert's scale ranging from strongly disagree to strongly agree (1-5).

\section{Operationalization}

The dimensions which represent the concept of team orientation of employee and associated elements of the dimensions were shown in Exhibit 1.

\section{Exhibit 1: Dimensions and Elements of Team Orientation of Employee}

\begin{tabular}{|l|l|}
\hline Dimensions (06) & Elements (29) \\
\hline (1)Team spirit & Willingness and feelings \\
& Cohesiveness \\
& Behavior \\
& Pride \\
& Loyalty \\
\hline (2) Cross functional teamwork & Complementary skill \\
& Support of sectional officers \\
& Level of participation \\
& Cooperation \\
\hline (3) Commonality of purpose & Breaking down barriers \\
& Clear team goal(s) \\
& Clear roles and responsibilities \\
& Acceptability \\
& Measurable goals \\
& Time frame \\
\hline (4) Agreement of organizational & Understandable \\
vision & Mutual agreement \\
& Visibility \\
& Link with team tasks \\
\hline (5) Leadership at branch level & Direction setting \\
& Trust \\
& Motivation and support \\
& Leadership style \\
& Inspiration \\
\hline
\end{tabular}




\begin{tabular}{|l|l|}
\hline (6) Communication & Open communication \\
& Express ideas and opinions \\
& Feedback \\
& Frequency of communication \\
& Team meeting \\
\hline
\end{tabular}

In addition to the TOE measure, respondents were asked to complete some demographics questions in the questionnaire. The study questionnaire includes questions on gender, age, educational qualification, grade, working section in a bank branch and experience in the current position.

\section{The Research Design}

\section{Material and Methods}

This study was a descriptive one because it was undertaken in order to describe and understand the team working practices, level of team orientation and investigating differences in the team orientation of employee according to their gender, age, education, grade, working section and experience of selected bank branch in the Trincomalee district. In this study, researchers have attempted to explore, describe and understand the concepts of team working practices and team orientation of employee of selected bank branches in the Trincomalee District.

The extent of the researchers' interference in the study was low because it did not affect the normal flow of activities. This study was carried out in a natural (non-contrived) environment where things or events occur normally.

This study was a cross-sectional one in the time horizon because data were collected from the secondary sources of the selected banks in one single point of time. Therefore, the unit of analysis was bank. In considering objective two and three also it was a cross-sectional one in the time horizon because data were collected in one single point of time from the respondents. But the unit of analysis was the individual employee of the selected bank branches in the Trincomalee district.

\section{Data Collection Sources and Methods}

In order to achieve the objective one of this study secondary data were collected mainly from the published annual reports of the selected banks such as State Bank 1 (SB-1), State Bank 2 (SB-2), Private Bank 1 (PB-1) and Private Bank 2 (PB-2) for the last four years $(2009,2010,2011$ and 2012). In order to achieve the second and third objectives of this study primary data were collected by the researchers by using self administered questionnaire. A structured questionnaire was designed for this study purpose and was distributed among the 115 bank staff of the selected four bank branches in the Trincomalee district.

\section{Sample Size, Method and Framework}

The total population for the study was 143 staff ( 55 employees from private banks and 88 from state banks) of selected banks in the Trincomalee district. Out of these employees, only 115 (51 employees from private banks and 64 from state banks) (80\%) were selected as sample by using stratified random sampling method. 


\section{Data Presentation and Analysis}

The data collected from the respondents in this study were presented by using tables and exhibits. In connection with objective one, the collected data was analyzed by using systematic content analysis. The number of team practices was counted from the collected data. In connection with second objective of this study, univariate analysis (descriptive statistics) has been adopted. In this analysis descriptive measures such as mean and standard deviation were used. Regarding third objective of this study, cross-tabulation analysis was used.

\section{Method of Data Evaluation}

Each dimension is given a scale from 1-5 to show the extent of agreement, based on responses, univariate measures were calculated for each of dimension. The mean value is lying in the range of 1-5 and the value of each respondent for a dimension is compared with the medium values of 3 . In evaluating the sample as a whole the mean value of the respondent is compared with the medium. If a respondent's average score of an aspect is less than the mean value (2.5) it is assumed that the respondent feels low level in team orientation in relation to the particular dimension. Thus, the decision rule to measure the level of team orientation can be formulated as follows given in Table 1.

Table 1: Decision Rule

\begin{tabular}{|c|l|}
\hline Range & \multicolumn{1}{c|}{ Decision Attributes } \\
\hline $1 \leq \mathrm{X} \leq 2.5$ & Low level of Team Orientation \\
\hline $2.5<\mathrm{X} \leq 3.5$ & Moderate level of Team Orientation \\
\hline $3.5<\mathrm{X} \leq 5.0$ & High level of Team Orientation \\
\hline
\end{tabular}

The criteria in Table 1 describes the attributes of the population in relation to particular dimension by considering aggregation of scales provided for every element of the respective dimension in the questionnaire.

\section{Results and Discussion: Objective One}

\section{Results and Discussion}

The first objective of this study is to explore the team working practices of selected state and private sector banks. In order to achieve this objective data were collected from the annual reports of selected banks. By using comprehensive and systematic content analysis researchers have developed Exhibit 2 and 3 in order to show team practices of selected state and private sector banks.

\section{Exhibit 2: Team Practices of Selected State Banks}

\section{State Bank 1 (SB-1)}

1. Recognize and rewards the best team of achievers in service excellence.

2. Setting goals and targets for the teams.

3. Evaluating the performance against the set team targets and goals periodically.

4. Cross functional team work and team working opportunities.

5. Team meeting held thrice during the year.

6. Encourage an effective extra-curricular regime of religious/sport and social activities in the bank in order to strength team work among the staff.

7. Promote mutual respects, openness, empowerment and delegation in the work setting.

State Bank 2 (SB-2)

1. Recognize team players in work setting. 
2. Creating opportunities for team players.

3. Empowering team players.

4. Having an environment of mutual respect and trust where employees can demonstrate their performance and achieve their full potential in teams.

5. Provide more priority to team players

6. Organizing annual sports meet island wide to strength the unity among the diverse workforce.

7. Team working opportunities.

8. Promote team building among their dynamic, dedicated work force to each individual with skills and knowledge appropriate to their task.

9. Bank launched staff Performance Incentive Scheme for teams.

(Source: Annual Reports of State Bank 1 and State Bank 2 - 2009, 2010, 2011 and 2012)

\section{Exhibit 3: Team Practices of Selected Private Banks}

\section{Private Bank (PB-1)}

1. Promoting Hatna Team and Family concept and inculcate the culture of unity in diversity among each and every staff member. 'The quality of interaction with the bank was further enhanced in 2009 through the adoption of a "Team Orientation" at branch level, thereby creating one of the largest teams in the financial series and banking industry in Sri Lanka'.

2. The bank's strategic objectives and goals have been achieved through teams/team working and creating a winning team.

3. Create an exciting work environment for the teams where rewards are performance-driven.

4. Implement cross functional committees representing the team at all hierarchical levels.

5. Harnessing a cordial relationship through harmonious industrial relations and assisting team members during crisis.

6. Identifying the best customer centre region-wide to aid the concepts of leadership, teamwork and high productivity.

7. In the annual awards ceremony recognizing excellent teamwork based on the performance of teams.

8. Use teams to thrive on new challenges.

9. Provides regular and ongoing feedback among the team members.

10. Communicating frankly and openly: A participatory style of communication, small team meetings, cross sectional meetings, monthly staff meetings practices are instrumental in giving all team members a platform to air their views with their immediate management superior and subsequently.

11. 'Search' or 'Spark' (Online) is a suggestions scheme that encourages team members to give their ideas and suggestions for the improvement of the bank and also inter-team relations.

12. The HR Newsletter also serves as one of the platforms in which the achievements of team members are commended.

13. In order to improve the Team Spirit among staff members, annually PB-1 organizes extracurricular activities, recreational efforts, talent spotting, family days, sports meets, festive and religious events.

14. The Private Bank 1 has always espoused the advantages of team spirit and culture of togetherness as the winning recipe for success.

15. Empowering people/staff members.

\section{Private Bank 2 (PB-2)}

1. Promoting the concept of 'One-Bank-One-Family' among the workforce.

2. Bank creates a dedicated team passionate about what they do and who on their own initiate, direct and synergizes their common creativity towards achieving continuous excellence.

3. Team Working (Employees working as team) and Knowledge Sharing.

4. Cross functional Team Program. 
5. Friendly and effective grievance communicating process.

6. Team Based Performance Management.

7. Team Based Rewarding.

8. Regular dialogue amongst all levels of staff and teams.

9. Organizing joint events and sports among all employees in order to promote team spirit.

10. Transparency in all activities.

(Source: Annual Reports of Private Bank 1 and Private Bank 2 - 2009, 2010, 2011 and 2012)

In connection with first objective, findings of the study revealed that both state and private sector banks are practicing many team practices, but relatively private sector banks have more team practices (25) than state sector banks (16). In the private sector banks PB-1 has more team practices (15) than PB-2 (10). At the same time in the state sector banks SB-2 and SB-1 have 9 and 7 team practices respectively. Cross functional team or teamwork, recognize team player, empowering employees toward teams, team meetings, organizing social and sports events in promoting team culture among the banks staff and providing opportunities to work as a team in various levels are some of most common team practices of banks which were considered in this study.

Apart from these facts, this secondary data analysis shows that how both sector banks in Trincomalee district have realized the importance of team in their day-to-day banking operation. But relatively private banks realized more about the team and team working practices because they have linked their teams or teamwork with their strategic objectives of the banks.

The selected private banks such as PB-1 and PB-2 are having all most similar team practices. An important fact that these two banks have deeply penetrated and innovative team practices into their operations. Example: PB-1 has 'Search' or 'Spark' (Online) that is a suggestions scheme encouraging team members to give their ideas and suggestions for the improvement of the bank and also inter-teams relations. Similarly PB-2 has knowledge sharing teams. From time to time these practices and policies are communicated by the banks to their employees through banks intranet, circulars, and notices etc. These are good examples that indicate how private sector banks are taking specific focus on their teams and teamwork innovatively.

\section{Results and Discussion: Objective Two}

The second objective of this study is to find out the level of team orientation of employee of selected state and private banks. In order to achieve this objective, data were collected from 115 employees of selected banks. The means and standard deviations of each dimension were presented in Table 2 and 3.

Table 2: Mean and Standard Deviation of each Dimension

\begin{tabular}{|l|c|c|}
\hline Banks and Dimensions & Mean & SD \\
\hline 1. Team spirit & & \\
\hline SB-1 (32) & 4.05 & 0.41 \\
\hline SB-2 (32) & 3.92 & 0.45 \\
\hline State Sector: (64) & $\mathbf{3 . 9 8}$ & $\mathbf{0 . 4 3}$ \\
\hline PB-1 (35) & 4.59 & 0.39 \\
\hline PB-2 (16) & 4.55 & 0.33 \\
\hline Private Sector: (51) & $\mathbf{4 . 5 8}$ & $\mathbf{0 . 3 7}$ \\
\hline
\end{tabular}




\begin{tabular}{|l|c|c|}
\hline 2. Cross-functional teamwork & & \\
\hline SB-1 (32) & 3.95 & 0.52 \\
\hline SB-2 (32) & 3.65 & 0.45 \\
\hline State Sector: (64) & $\mathbf{3 . 8 0}$ & $\mathbf{0 . 5 0}$ \\
\hline PB-1 (35) & 4.21 & 0.50 \\
\hline PB-2 (16) & 4.11 & 0.49 \\
\hline Private Sector: (51) & $\mathbf{4 . 1 8}$ & $\mathbf{0 . 4 9}$ \\
\hline 3. Commonality of purpose & & \\
\hline SB-1 (32) & 3.86 & 0.59 \\
\hline SB-2 (32) & 3.64 & 0.47 \\
\hline State Sector: (64) & $\mathbf{3 . 7 5}$ & $\mathbf{0 . 5 3}$ \\
\hline PB-1 (35) & 4.01 & 0.54 \\
\hline PB-2 (16) & 4.13 & 0.37 \\
\hline Private Sector: (51) & $\mathbf{4 . 0 5}$ & $\mathbf{0 . 4 8}$ \\
\hline 4. Overall agreement of vision & & \\
\hline SB-1 (32) & 3.92 & 0.77 \\
\hline SB-2 (32) & 3.84 & 0.38 \\
\hline State Sector: (64) & $\mathbf{3 . 8 8}$ & $\mathbf{0 . 6 0}$ \\
\hline PB-1 (35) & 4.19 & 0.46 \\
\hline PB-2 (16) & 3.95 & 0.26 \\
\hline Private Sector: (51) & $\mathbf{4 . 1 1}$ & $\mathbf{0 . 4 1}$ \\
\hline 5. Leadership at branch level & & \\
\hline SB-1 (32) & 3.90 & 0.89 \\
\hline SB-2 (32) & 3.80 & 0.46 \\
\hline State Sector: (64) & $\mathbf{3 . 8 5}$ & $\mathbf{0 . 7 0}$ \\
\hline PB-1 (35) & 4.14 & 0.48 \\
\hline PB-2 (16) & 4.26 & 0.45 \\
\hline Private Sector: (51) & $\mathbf{4 . 1 8}$ & $\mathbf{0 . 4 7}$ \\
\hline 6. Communication & 3.96 & \\
\hline SB-1 (32) & 3.76 & 0.78 \\
\hline SB-2 (32) & $\mathbf{3 . 8 6}$ & $\mathbf{0 . 6 6}$ \\
\hline State Sector: (64) & 4.05 & 0.46 \\
\hline PB-1 (35) & 4.09 & 0.59 \\
\hline PB-2 (16) & $\mathbf{4 . 0 6}$ & $\mathbf{0 . 4 9}$ \\
\hline Private Sector: (51) & & \\
\hline
\end{tabular}

Table 3: Banks and Mean Values of Dimensions

\begin{tabular}{|l|c|c|c|c|}
\hline Bank/ & SB-1 & SB-2 & PB-1 & PB-2 \\
Dimensions & $\mathbf{( 3 2 )}$ & $\mathbf{( 3 2 )}$ & $\mathbf{( 3 5 )}$ & $\mathbf{( 1 6 )}$ \\
\hline Team spirit & 4.05 & 3.92 & 4.59 & 4.55 \\
\hline Cross functional teamwork & 3.95 & 3.65 & 4.21 & 4.11 \\
\hline Commonality of purpose & 3.86 & 3.64 & 4.01 & 4.14 \\
\hline Agreement of organizational vision & 3.92 & 3.84 & 4.18 & 3.95 \\
\hline Leadership at branch level & 3.90 & 3.80 & 4.14 & 4.26 \\
\hline Communication & 3.97 & 3.76 & 4.05 & 4.09 \\
\hline Overall Team orientation & $\mathbf{3 . 9 4}$ & $\mathbf{3 . 7 7}$ & $\mathbf{4 . 1 9}$ & $\mathbf{4 . 1 8}$ \\
\hline
\end{tabular}


The results of the study showed that there is a higher level of team orientation among the employees of the four banks (mean value was above 3.5) but there were slight differences observed. The mean values for the PB-1, PB-2, SB-1 and SB-2 were 4.19, 4.18, 3.94 and 3.77 respectively. The mean scores for all the dimensions representing team orientation were high in the perception of bank employees. But in considering all the dimensions we can observe that there are some gaps between the private and state sector banks. It indicates that state sector banks must pay special attention toward developing team orientation among their staff members in the Trincomalee district. Regarding banking sector, there are no specific literature or research findings similar to this nature. Therefore, this trend does not permit the researchers to discuss more deeply regarding the findings of this study. At the same time results of this study lead us to think or give a certain key message that sector of a bank (private or state) may be a determinant of team orientation of the bank employee.

\section{Results and Discussion: Objective Three}

The third of objective of this study is to investigate whether team orientation of employee gets differed according to the employee's gender, age, education, grade, working section and experience. In order to achieve this objective cross-tabulation analysis was performed. In the cross-tabulation analysis, personal information was cross-tabulated with the mean values of dimensions representing the team orientation of employee of selected banks.

\section{Gender}

The gender distribution of the sample consists of 64 males and 51 females. The mean values of dimensions based on gender were presented in Table 4.

Table 4: Gender and Mean Values of Dimensions - Cross Tabulation

\begin{tabular}{|l|c|c|}
\hline Gender & $\begin{array}{c}\text { Male } \\
(\mathbf{6 4})\end{array}$ & $\begin{array}{c}\text { Female } \\
(\mathbf{5 1})\end{array}$ \\
\hline Team spirit & 4.36 & 4.12 \\
\hline Cross functional teamwork & 3.99 & 3.95 \\
\hline Commonality of purpose & 3.92 & 3.83 \\
\hline Agreement of organizational vision & 4.00 & 3.96 \\
\hline Leadership at branch level & 3.99 & 4.00 \\
\hline Communication & 3.97 & 3.94 \\
\hline Overall Team orientation & $\mathbf{4 . 0 4}$ & $\mathbf{3 . 9 6}$ \\
\hline
\end{tabular}

Age

The respective mean values of dimensions based on 3 age groups were presented in Table 5 .

Table 5: Age and Mean Values of Dimensions - Cross Tabulation

\begin{tabular}{|l|c|c|c|}
\hline Age & $\begin{array}{c}\text { Below 25 } \\
(\mathbf{2 8})\end{array}$ & $\begin{array}{c}\text { Between 26-50 } \\
(\mathbf{7 7})\end{array}$ & $\begin{array}{c}\text { Above 50 } \\
(\mathbf{1 0})\end{array}$ \\
\hline Team spirit & 4.21 & 4.31 & 3.92 \\
\hline Cross functional teamwork & 4.01 & 3.96 & 3.96 \\
\hline Commonality of purpose & 3.89 & 3.88 & 3.88 \\
\hline Agreement of organizational vision & 4.00 & 3.99 & 3.90 \\
\hline Leadership at branch level & 4.17 & 3.97 & 3.74 \\
\hline Communication & 4.06 & 3.94 & 3.77 \\
\hline Overall Team orientation & $\mathbf{4 . 0 6}$ & $\mathbf{4 . 0 1}$ & $\mathbf{3 . 8 6}$ \\
\hline
\end{tabular}




\section{Educational Qualification}

The mean values of dimensions based on 6 categories of educational qualifications were presented in Table 6 .

Table 6: Education and Mean Values of Dimensions - Cross Tabulation

\begin{tabular}{|l|c|c|c|c|c|c|}
\hline Education & $\begin{array}{c}\text { Up to } \\
\mathbf{O} / \mathbf{L} \\
(\mathbf{0 8})\end{array}$ & $\begin{array}{c}\text { Up to } \\
\mathbf{A} / \mathbf{L} \\
\mathbf{( 3 6 )}\end{array}$ & $\begin{array}{c}\text { Bachelor } \\
\text { Degree } \\
\mathbf{( 3 0 )}\end{array}$ & $\begin{array}{c}\text { Masters } \\
\text { Degree } \\
(\mathbf{0 7})\end{array}$ & $\begin{array}{c}\mathbf{C B F} \\
\mathbf{( 1 0 )}\end{array}$ & $\begin{array}{c}\text { DBF } \\
(\mathbf{2 4})\end{array}$ \\
\hline Team spirit & 3.82 & 4.17 & 4.39 & 4.23 & 4.26 & 4.35 \\
\hline Cross functional team work & 3.55 & 3.90 & 3.96 & 4.03 & 4.14 & 4.13 \\
\hline Commonality of purpose & 3.52 & 3.83 & 3.87 & 4.26 & 4.08 & 3.92 \\
\hline $\begin{array}{l}\text { Agreement of organizational } \\
\text { vision }\end{array}$ & 3.69 & 3.89 & 3.97 & 4.50 & 4.07 & 4.05 \\
\hline Leadership at branch level & 3.45 & 3.92 & 3.97 & 4.43 & 4.10 & 4.16 \\
\hline Communication & 3.56 & 3.92 & 3.87 & 4.31 & 3.93 & 4.15 \\
\hline Overall Team orientation & $\mathbf{3 . 6 0}$ & $\mathbf{3 . 9 4}$ & $\mathbf{4 . 0 0}$ & $\mathbf{4 . 2 9}$ & $\mathbf{4 . 1 0}$ & $\mathbf{4 . 1 3}$ \\
\hline
\end{tabular}

\section{Grade}

The grade of the employees of the selected state and private sector banks and mean values of dimensions based on 4 grades were presented in Table 7.

Table 7: Grade and Mean Values of Dimensions - Cross Tabulation

\begin{tabular}{|l|c|c|c|c|}
\hline Grade & $\begin{array}{c}\text { Banking } \\
\text { Assistant } \\
\mathbf{( 5 2 )}\end{array}$ & $\begin{array}{c}\text { Clerical } \\
\text { staff } \\
\mathbf{( 2 1 )}\end{array}$ & $\begin{array}{c}\text { Office } \\
\text { Assistant } \\
\mathbf{( 2 0 )}\end{array}$ & $\begin{array}{c}\text { Junior } \\
\text { Executive \& } \\
\text { Branch } \\
\text { Managers } \\
\mathbf{( 2 2 )}\end{array}$ \\
\hline Team spirit & 4.32 & 4.20 & 4.14 & 4.24 \\
\hline Cross functional teamwork & 4.06 & 3.95 & 3.77 & 3.96 \\
\hline Commonality of purpose & 3.80 & 3.95 & 3.90 & 4.00 \\
\hline $\begin{array}{l}\text { Agreement of organizational } \\
\text { vision }\end{array}$ & 3.90 & 4.07 & 3.99 & 4.10 \\
\hline Leadership at branch level & 3.99 & 4.09 & 3.88 & 4.02 \\
\hline Communication & 3.93 & 4.09 & 3.88 & 3.95 \\
\hline Overall Team orientation & $\mathbf{4 . 0 0}$ & $\mathbf{4 . 0 6}$ & $\mathbf{3 . 9 3}$ & $\mathbf{4 . 0 4}$ \\
\hline
\end{tabular}

\section{Working Section}

The working section of the employees of the selected state and private sector banks and mean values of dimensions based on 6 sections of works were presented in Table 8 .

Table 8: Working Section and Mean Values of Dimensions -Cross Tabulation

\begin{tabular}{|l|c|c|c|c|c|c|}
\hline Working Section & $\mathbf{A}$ & $\mathbf{B}$ & $\mathbf{C}$ & $\mathbf{D}$ & $\mathbf{E}$ & $\mathbf{F}$ \\
& $\mathbf{( 2 4 )}$ & $\mathbf{( 1 6 )}$ & $\mathbf{( 1 7 )}$ & $\mathbf{( 3 2})$ & $\mathbf{( 1 0 )}$ & $\mathbf{( 1 6 )}$ \\
\hline Team spirit & 4.32 & 4.27 & 4.02 & 4.28 & 4.18 & 4.35 \\
\hline Cross functional team work & 3.98 & 4.17 & 3.81 & 3.99 & 3.66 & 4.06 \\
\hline Commonality of purpose & 3.76 & 3.92 & 3.88 & 3.91 & 3.76 & 4.06 \\
\hline Agreement of organizational vision & 3.84 & 4.01 & 4.03 & 3.97 & 4.07 & 4.09 \\
\hline
\end{tabular}




\begin{tabular}{|l|l|l|l|l|l|l|}
\hline Leadership at branch level & 4.04 & 3.86 & 4.02 & 3.97 & 4.08 & 4.02 \\
\hline Communication & 3.94 & 3.95 & 3.95 & 3.88 & 4.18 & 3.99 \\
\hline Overall Team orientation & $\mathbf{3 . 9 8}$ & $\mathbf{4 . 0 3}$ & $\mathbf{3 . 9 5}$ & $\mathbf{4 . 0 0}$ & $\mathbf{3 . 9 9}$ & $\mathbf{4 . 1 0}$ \\
\hline Note: A - Counter, B - Personal Banking Unit \\
$\quad$ C - Pawning, D - Loan, \\
E - Accounting and Reporting and F - Others \\
\hline
\end{tabular}

\section{Work Experience}

The experiences of the employees of the selected state and private sector banks and mean values of dimensions based on 3 categories of experiences were presented in Table 9.

Table 9: Working Experience and Mean Values of Dimensions -Cross Tabulation

\begin{tabular}{|l|c|c|c|} 
Work & $\begin{array}{c}\text { Below 5 } \\
\text { years } \\
(\mathbf{7 8})\end{array}$ & $\begin{array}{c}\text { Between } \\
\text { 5-10 years } \\
(\mathbf{2 7})\end{array}$ & $\begin{array}{c}\text { Above } \\
\mathbf{1 0} \text { years } \\
(\mathbf{1 0 )}\end{array}$ \\
\hline Team spirit & 4.25 & 4.32 & 4.02 \\
\hline Cross functional teamwork & 4.02 & 3.87 & 3.88 \\
\hline Commonality of purpose & 3.88 & 3.98 & 3.70 \\
\hline Agreement of organizational vision & 3.97 & 4.06 & 3.90 \\
\hline Leadership at branch level & 3.99 & 4.09 & 3.76 \\
\hline Communication & 3.93 & 4.09 & 3.77 \\
\hline Overall Team orientation & $\mathbf{4 . 0 1}$ & $\mathbf{4 . 0 7}$ & $\mathbf{3 . 8 4}$ \\
\hline
\end{tabular}

In cross-tabulating the overall level of team orientation of employees with their gender, age, education, grade, working section and experiences, some differences in the crosstabulations can be observed. When comparing male and female employees, male employees have fairly higher level of team orientation than female employees. When comparing three different employee age groups, below 25 have more team orientation than other groups (Between 26-50 and Above 50). Also the above 50 age group has relatively low level of team orientation when compared with below 25 and between 26-50. Comparing six different educational qualifications relatively master's degree holders have higher level of team orientation than others. In comparing the grade, employees who belonged to the clerical staff grade have higher level of team orientation. Based on working section of the employees, relatively personal banking unit and others have higher level of team orientation in considering the six different working sections. Finally comparing employees' experiences people who have 5-10 years experience have higher level of teamorientation than other two ranges. Employees who have more than 10 years experience have relatively low level of team orientation.

Based on the finding regarding these demographic or personal factors of employees toward team orientation, banks must focus on these aspects of employees in developing and implementing team working practices in their bank branches commonly.

\section{Conclusions}

As far as this study is concerned both sector banks have many team working practices. But private sector banks have well designed team working practices when compared with state sector banks. Regarding the level of team orientation of employee, both sector banks have high level of team orientation but there are some differences observed among the selected banks in this study. Investigating demographic factors such as gender, age, education, 
grade, working section and experiences with team orientation, differences can be observed among the employees of selected banks in the Trincomalee district. Findings of the study will be useful and important in understanding empirical knowledge regarding the concepts of team working practices and team orientation of employee of selected banks.

\section{Acknowledgement}

The authors wish to thank Senior Professor (Dr.) H. H. D. N. P. Opatha for his valuable and constructive comments on earlier version of this paper.

\section{References}

Anton Arulrajah, A., and Opatha, H. H. D. N. P. (2012), 'An Exploratory Study on the Personal Qualities/Characteristics expected by the Organizations for Key HRM jobs in Sri Lanka', Sri Lankan Journal of Human Resource Management, Vol.3(1), pp. 32-48.

Bank of Ceylon Annual Reports (2009, 2010, 2011 and 2012), Bank of Ceylon of Sri Lanka, Colombo: Sri Lanka.

Clegg, B. (2000), Team spirit: Instant Motivation, India: Vinod Vasishtha.

Commercial Bank of Ceylon, Annual Reports (2009, 2010, 2011 and 2012), Commercial Bank of Ceylon, Colombo: Sri Lanka.

Driskell, J. E. and Salas, E. (1992) Collective behavior and team performance. Human Factors, 34, pp. 277-288.

Eby, L. T. and Dobbins, G. H. (1997) "Collectivistic orientation in teams: an individual and group-level analysis”, Journal of Organizational Behavior, 18, pp 275-295.

Hatton National Bank Annual Reports (2009, 2010, 2011 and 2012), Hatton National Bank in Sri Lanka, Colombo: Sri Lanka.

Hult, G.T.M. and Nichols, E.L (1999) "A study of team orientation in global purchasing", Journal of Business \& Industrial Marketing, MCB UP Ltd, Vol.14, No.3, 1999, pp.194-212.

Kleiman, L. S (1997), Human Resource Management, A Tool for Competitive Advantage, USA: West Publishing Company, New York.

O'Shea, P.G, Driskell, J.E, Goodwin, G.F, Zbylut, M.L and Weiss, S.M (2004), Development of Conditional Reasoning Measure of Team Orientation, ARI Research Note: 2004-10, Leader Development Research Unit, U.S Army Research Institute for the Behavioral and Social Sciences.

Parker, W. and Pankowski, M. (1990), A Handbook for Team-Based Organizations, Teams in Government, New York: Lucie Press.

People's Bank Annual Reports (2009, 2010, 2011 and 2012), People's Bank, Sri Lanka, Colombo: Sri Lanka.

Shaw, M.E. (1981), Group dynamics: The Psychology of small group behaviour, third edition, New York: McGraw-Hill.

Wageman, R. (1995), "Interdependence and group effectiveness". Administrative Science Quarterly, 40, pp. 145-180. 